\title{
Effects of Evaporator and Condenser Temperatures on the Performance of a Chiller System With a Variable Speed Compressor
}

\author{
Ahmed H. Al-Hassani ${ }^{a^{*}}$, Alaa R. Al-Badri ${ }^{b}{ }^{b}$ \\ ${ }^{a}$ Mechanical Engineering Department, University of Wasit, Al-Kut, Iraq. ahasany@uowasit.edu.iq \\ ${ }^{\mathrm{b}}$ Mechanical Engineering Department, University of Wasit, Al-Kut, Iraq. albadria@uowasit.edu.iq \\ *Corresponding author.
}

Submitted: $17 / 03 / 2020$

Accepted: 27/05/2020

Published: 25/01/2021

K E Y W O R D S

Variable speed compressor, Water chiller temperature, EEV, PI controller, R410a

\author{
A B S T R A C T
}

The operation and performance of heat-pump systems are affected by indoor and outdoor operating conditions. Power consumption and system efficiency are related to evaporator and condenser working pressures. Intelligent controllers such as a proportional integral (PI) controller improve the performance of variable speed refrigeration systems (VSRs) with electronic expansion valve (EEV). Evaporator and condenser pressures affect the system power consumption and efficiency. In this study, the influence of evaporator and condenser temperatures on the performance of a variable speed refrigeration system with an EEV was experimentally investigated at constant cooling load. The experimental system comprises of a rotary compressor, shell-and-coil condenser, EEV, and shell-and-coil evaporator for one-ton cooling capacity with refrigerant R410. Compressor speed and EEV opening are controlled by a $P I$ controller with two control loops and the refrigerant superheat (DS) is maintained at $7^{\circ} \mathrm{C}$. The results show that at constant cooling capacity, the refrigerant flow rate rises with the increase in the compressor speed. The coefficient of performance (COP) is improved with low compressor speed. The System COP is increased by 3.3\% with increasing evaporator inlet water temperature for $2^{\circ} \mathrm{C}$ due to the reduction in the compressor speed and compression ratio. High condenser inlet water temperature promotes the refrigerant subcooling.

\footnotetext{
How to cite this article: A. H. Al-Hassani and A. R. Al-Badri, "Effects of evaporator and condenser temperatures on the performance of a chiller system with a variable speed compressor," Engineering and Technology Journal, Vol. 39, Part A, No. 01, pp. 45-55, 2021. DOI: https://doi.org/10.30684/etj.v39i1A.1647

This is an open access article under the CC BY 4.0 license http://creativecommons.org/licenses/by/4.0
}

\section{INTRODUCTION}

Energy saving in variable speed refrigeration system (VSRs) depends on the pressure ratio between condenser and evaporator pressures that is related to their working temperatures and on the 
compressor's speed [1]. The variation in the cooling capacity by using variable speed compressors equipped with an electronic expansion valve requires intelligent controllers to achieve optimum performance. The effect of compressor speed variation and EEV opening on the power consumption and refrigeration rate in cooling chiller systems was numerically investigated by Koury et al. [2]. The results of a numerical simulation showed that when the compressor speed increased, the COP decreased because of higher power consumption in spite of the increase in refrigeration effect. An increase in the EEV opening will increase the COP as well with a limit of safety for compressor operation. This simulation presented a relationship between compressor speed and EEV opening which achieves maximum system performance. The effects of operating conditions on system power consumption were investigated by Aprea et al. [3] for cooling and heating modes. They compared between constant frequency reciprocating compressor and variable frequency scroll compressor refrigeration systems. Operation conditions were at constant thermal load with different temperature sets for evaporator and condenser. The experimental results showed that constant speed compressor consumed higher energy compared to variable speed compressor at all operating conditions. In addition, power can be also saved by increasing the evaporator temperature or by decreasing the condenser temperature. Qiu et al. [4] developed a dynamic model for control a variable refrigerant flow system including variable speed compressor, EEV, and sub-cooler. The effect of coupling between compressor speed and EEV opening on the performance and stability of this system was studied. The optimum energy efficiency ratio was at narrow EEV opening under part-load condition. Narrow EEV opening affected the amount of refrigerant subcooled at certain compressor speed which led to increasing refrigeration capacity.

Refrigerant superheats affect system stability, coefficient of performance, and the compressor saving for a variable speed refrigeration system. Superheat control is a difficult task due to the nonlinearity of the VSRs response and with time delay [5]. High DS value leads to low COP but it saves compressor against damage from refrigerant liquid drops. EEV opening affects the system stability at high DS values that results in a continuous fluctuation in temperature and pressure that is defined as hunting [6]. The phenomenon of hunting is one of the drawbacks in the VSRs because it leads to lower operation safety and higher power consumption. In variable speed compressor systems, hunting is very common due to changes in compressor speed and EEV opening. Xia et al. [5] studied the effect of evaporator temperature and compressor speed on the degree of refrigerant superheat by experiments on the R410 a direct expansion (DX) system with an EEV controlled by a PI-controller. The experimental results show that the none linearity between the EEV opening and refrigerant mass flow rate led to more chances for hunting especially at low compressor speed or low evaporating temperature. Time delay of EEV working was one of the important reasons for the unstable operation in variable speed compressor systems. This delay comes from (stepper coil of the EEV, controller loop, and the sensors of the feedback signal). Varchmin et al. [7] developed a new PI controlling method with a forwarding signal of compressor speed and evaporation temperature to control the DS in a variable speed chiller system with R134a. The results show more stability with a fast response for the new controller compared with the previous one. The nonlinearity of the DS response to EEV opening was investigated by Yan et al. [8] to develop an adaptive PI controller depending on the evaporator operating conditions. Proportional gain $(\mathrm{kp})$ and time constant were functions of evaporator fan speed in the $\mathrm{DX}$ variable-speed $\mathrm{A} / \mathrm{C}$ system. The experimental controllability tests show that the response of DS with the adaptive PI controller is more stable and faster than the On/Off method. Guo et al. [9] proposed a power correlation with input variables (frequency, evaporator and condenser temperatures) and 20 constant coefficients obtained from experimental data for a variable speed refrigerant flow air condition system. Experimental data showed high power consumption at high condensation temperature and high compressor speed. Increasing evaporation temperature decreased power consumption especially at high compressor speed and condenser temperature. Prsic et al. [10] studied the effects of evaporator static characteristics and the EEV on the degree of refrigerant superheat for a chiller system with R410a refrigerant. The numerical results displayed that high limit of DS value was depended on the stability of the system to avoid hunting and that low DS limit was depended on evaporator inlet water temperature to maintain the compressor. Friction inside the EEV will be affected signal delay in time response and also noise from temperature sensors which led to hunting. System stability was 
improved using a describing function that depended on a static characteristic of the EEV to generate the controlling signal.

This research study aims to experimentally investigate the effects of evaporator and condenser inlet water temperatures on the performance and characteristics of a water chiller refrigeration system. Refrigerant subcooled, mass flow rate, condenser pressure, evaporator pressure, and power consumption are taken into consideration. In the following, the experimental apparatus is presented. Then, the results along with conclusions of the present work are explained.

\section{EXPERIMENTAL RIG}

A model of water chiller system was used as an experimental rig equipped with variable speed twin rotary compressor and EEV which was charged with the refrigerant R410a (50\% R32 and 50\% R125) for one-ton cooling capacity. Two shell and coil copper tube heat exchangers are used as evaporator and condenser to exchanging heat with the secondary fluid (water). Coil copper tube diameter was $9.5 \mathrm{~mm}$ with tube length of 6.5 and $9.5 \mathrm{~m}$ for evaporator and condenser respectively. Figure 1, shows a sketch diagram of the experimental rig.

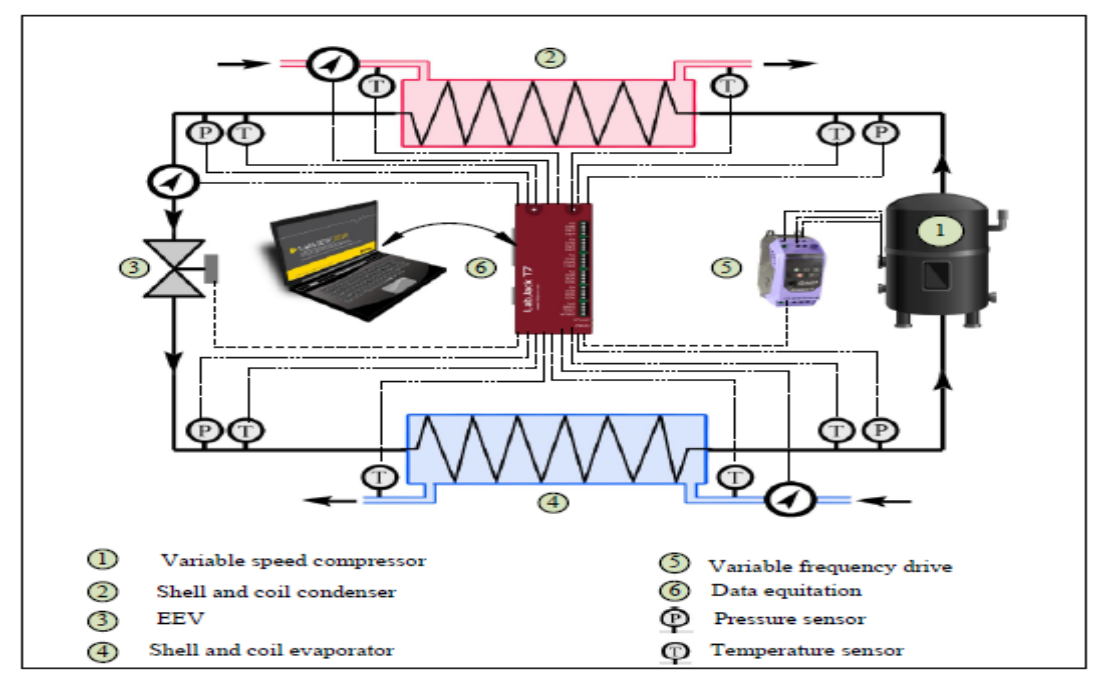

Figure 1: Schematic of the apparatus

The pressure and temperature sensors were mounted at the refrigerant inlet and outlet for each heat exchanger. Pressure sensors have a range of $0-40$ bar with uncertainty range \pm 0.3 bar. The temperature sensors were NTC-10K $\Omega$ type with uncertainty range $\pm 0.3^{\circ} \mathrm{C}$ with a temperature range between -20 to $120^{\circ} \mathrm{C}$. Refrigerate flow rate is measured by a refrigerant flow meter which was suitable for refrigerant R410a with a flow range of $0.2-2 \mathrm{~L} / \mathrm{min}$ and error $\pm 0.354 \mathrm{~mL} / \mathrm{s}$ by McMillan (S-114-7). The compressor speed is regulated from 1200 to $3600 \mathrm{rpm}$ by using a variable frequency drive model (ODE-140041-3F12) for brushless direct current motors which is controlled by a $0-5 \mathrm{v}$ signal with error $\pm 0.5 \%$. Power consumed by the system was measured by a power meter YIGEDIANQI model YG889-9SY (power, voltage, current, and frequency) digital 3-phase meter. Data acquisition (LabJACK-T7pro) connected with (LabVIEW-2018) software is used to record sensors data and also to control compressor speed and EEV opening by a signal $0-5 \mathrm{v}$. The water inlet and outlet temperatures of the evaporator and condenser, as well as the volumetric flow rate, were measured. The degree of superheat value is calculated from Eq. (1) based on the difference between evaporator outlet refrigerant temperatures $\left(T_{e, r, o}\right)$ and refrigerant saturation temperature at evaporator outlet pressure $\left(T_{e, r, s}\right)[10]$.

$$
D S=T_{e, r, o}-T_{e, r, s}
$$

The coefficient of performance $(C O P)$ was calculated depending on the output refrigeration rate from the evaporator $\left(Q_{e}\right)$ based on the water temperature difference from Eq. (2). 


$$
C O P=\frac{Q_{e}}{W}=\frac{\dot{m}_{w^{*}} C_{p^{*}}\left(T_{e, w, i}-T_{e, w, o}\right)}{W}
$$

Where $\left(\dot{m}_{w}\right)$ water flow rate, $\left(C_{p}\right)$ specific heat capacity of water which equals $4.19 \mathrm{~kJ} / \mathrm{kg} . \mathrm{K},(W)$ system power consumption and $\left(T_{e, w, i}, T_{e, w, o}\right)$ evaporator inlet and outlet water temperatures respectively.

Compressor speed was controlled by PI controller depending on the temperature difference between the set cold and product water temperature. EEV opening was regulated depending on the difference between the refrigerant superheat outlet from evaporator and its set value $\left(7^{\circ} \mathrm{C}\right)$ by a second controlling loop with PI controller as shown in Figure 2.

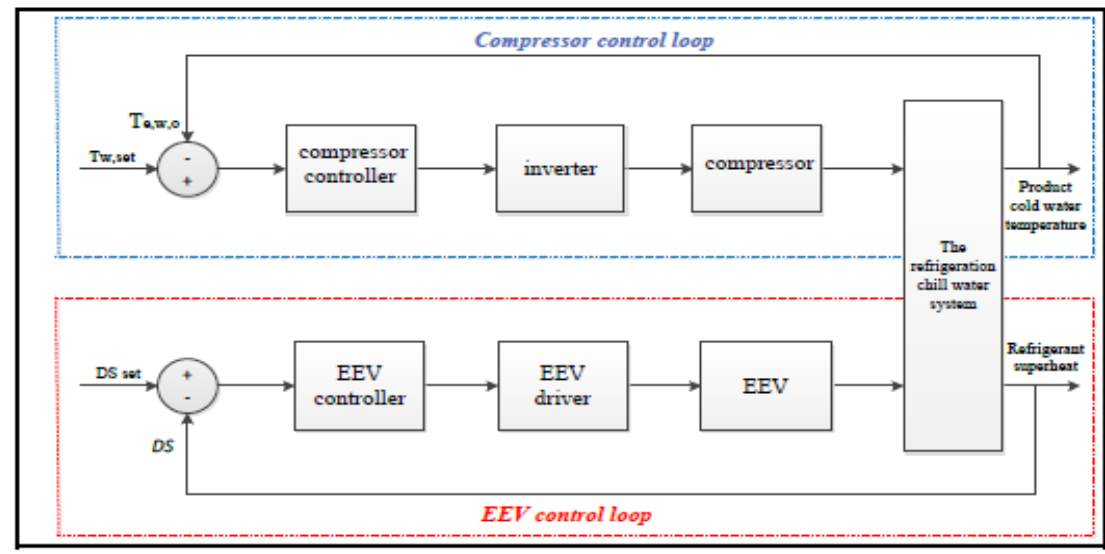

Figure 2: Control Block diagram of the experimental system

The proportional and integral (PI) controller is widely used in variable speed refrigeration systems because of simple structure and low cost in addition to acceptable performance[11]. Figure 3 shows a sketch diagram of PI-controller.

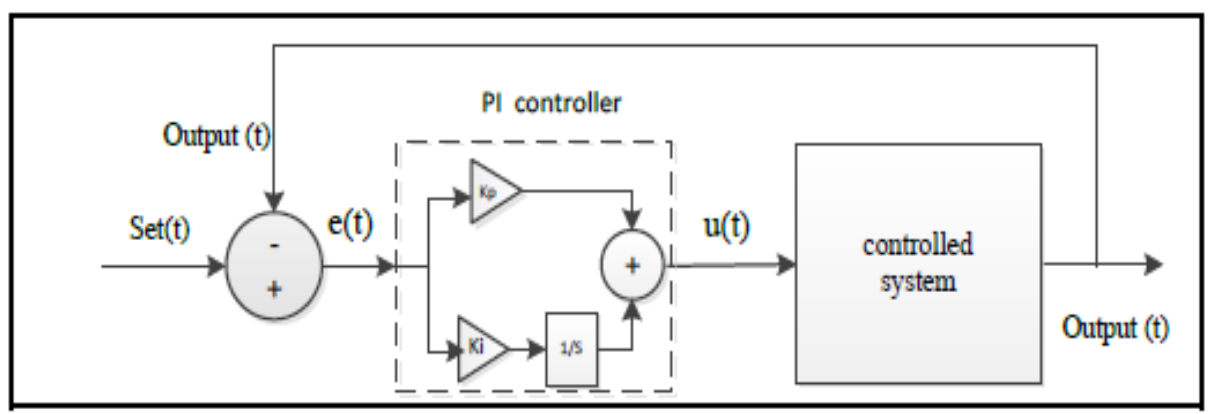

|Figure 3: Block diagram of the PI-controller [12]

The output signal $u(t)$ from the PI-controller is calculated from Eq. (3), which consist of the summation of the two terms [12]:

1) A proportional term is the main effect to reduce the error from multiply the difference value by the proportional gain $\left(\mathrm{k}_{\mathrm{p}}\right)$.

2) An integral term reduces the study state error by multiply the time integral of the change in the difference value with the integral gain $\left(\mathrm{k}_{\mathrm{i}}\right)$.

$$
u(t)=k_{p} \times e(t)+k_{i} \times \int e(t) d t
$$

Where $e(t)$ is the error signal that calculates based on the temperature difference of the product cold water temperature for compressor controller and the difference in refrigerant superheat for EEV controller. 


\section{PI-CONTROLLERS TUNING}

Tuning is defined as the process to determine the optimum controller gains [13] which, in this study, was performed by trial and error method. The tuning process was achieved in two steps. First, the compressor controller was tuned while the EEV opening was directly regulated by an empirical equation. This equation was inferred based on our experiments. Then, the EEV controller was tuned in the second step. The proportional integral controller has two gains which are $k_{p}$ and $k_{i}$. The results of the tuning process are presented in Figure 4.

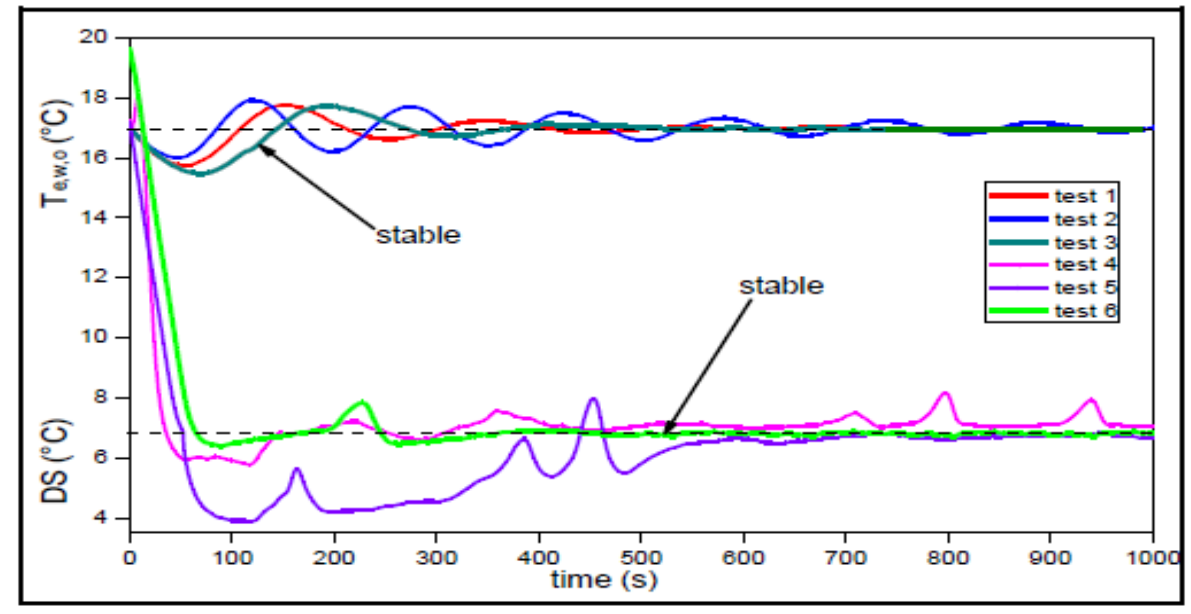

Figure 4: Tuning process test results for the PI-controllers

Here, the changes in the degree of superheat and cold water temperature with time are demonstrated. Six tests were performed to find the most stable operation of the system. Test variables are presented in Table I. By comparison between these six tests, stable operation of the compressor and the EEV with PI-controller is obtained with test three $\left(\mathrm{k}_{\mathrm{p}}=0.02, \mathrm{k}_{\mathrm{i}}=0.002\right)$ and test $\operatorname{six}\left(\mathrm{k}_{\mathrm{p}}=0.8\right.$, $\mathrm{k}_{\mathrm{i}}=0.01$ ) respectively.

TABLE I: PI controller tuning results

\begin{tabular}{cccccc}
\hline \hline \multirow{2}{*}{ Test No. } & \multicolumn{2}{c}{ compressor controller gains } & \multicolumn{2}{c}{ EEV controller gains } \\
\cline { 2 - 4 } & $\boldsymbol{k}_{\boldsymbol{p}}$ & $\boldsymbol{k}_{\boldsymbol{i}}$ & & $\boldsymbol{k}_{\boldsymbol{p}}$ & $\boldsymbol{k}_{\boldsymbol{i}}$ \\
\hline test 1 & 0.03 & 0.0003 & & \multirow{2}{*}{ At first, controlled by equation } \\
test 2 & 0.03 & 0.002 & & \multicolumn{2}{c}{ for EEV opening } \\
\hline test 3 & $\mathbf{0 . 0 2}$ & $\mathbf{0 . 0 0 2}$ & & 1.5 & 0.001 \\
\hline test 4 & 0.02 & 0.002 & & 1 & 0.01 \\
\hline test 5 & 0.02 & 0.002 & $\mathbf{0 . 8}$ \\
\hline test 6 & 0.02 & 0.002 & $\mathbf{0 . 0 1}$ \\
\hline
\end{tabular}

\section{UNCERTAINTY ANALYSIS}

Uncertainty in final results indicates the amount of deviation from a true value [14]. Measurement devices have a fixed error, which is related to the manufactures and a random error that results from the effects during measurement process. The fixed error was reduced by a calibration process for all sensors and meters and also, random error was identified from the experimental results in the control and measurement laboratory at steady state conditions. The uncertainty in the coefficient of performance $\left(\mathrm{U}_{\mathrm{COP}}\right)$ was evaluated depending on the method of multi-samples uncertainty analysis [15]. This method depends on the fixed and random error determination for each measured quantity $\left(x_{i}\right)$ by Eq. (4).

$$
U_{C O P}=\left[\sum_{i=1}^{n}\left(\frac{\partial C O P}{\partial x_{i}} \delta x_{i, f}\right)^{2}+\sum_{i=1}^{n}\left(\frac{\partial C O P}{\partial x_{i}} \delta x_{i, r}\right)^{2}\right]^{1 / 2}
$$


Where $\left(x_{i, f}\right)$ and $\left(x_{i, r}\right)$ the fixed and random errors of the measured variable $\left(x_{i}\right)$, and $(n)$ is the number of measurands. The COP is a function of water flow rate, evaporator inlet, and outlet water temperatures, and power, see Eq. (2). The random error was calculated for each measurand by the following equation [15]:

$$
\delta x_{i, r}=\frac{t * \sigma_{i}}{\sqrt{N}}
$$

Where $\left(\sigma_{\mathrm{i}}\right)$ is the samples' standard deviation, (t) was chosen to be (2) with a confidence level of $95 \%$ which corresponds to the degree of freedom $(\mathrm{N}-1)$ and $(\mathrm{N})$ is the number of samples. The fixed error of the temperature sensors, water flow meter, and power meter were $(1 \%, 2 \%$, and $0.5 \%)$ respectively, according to the manufacturer's data and the uncertainty range in these measurements was $\pm 0.3^{\circ} \mathrm{C}, \pm 1.8 \mathrm{~mL} / \mathrm{s}$, and $6.5 \mathrm{w}$ under steady state conditions. The uncertainty limits of the COP were 4.5 to $6.8 \%$.

\section{RESULTS AND DISCUSSIONS}

The evaporator inlet water temperature $\left(\mathrm{T}_{\mathrm{e}, \mathrm{w}, \mathrm{i}}\right)$ was changed by $\left(15,17\right.$, and $\left.19^{\circ} \mathrm{C}\right)$ while the condenser inlet water temperature $\left(\mathrm{T}_{\mathrm{c}, \mathrm{w}, \mathrm{i}}\right)$ was varied by $\left(25,27,29,31\right.$, and $\left.33^{\circ} \mathrm{C}\right)$. The experimental data were recorded at steady state conditions and constant cooling load. The constant cooling load was achieved by keeping constant difference between $T_{e, w, i}$ and $T_{e, w, o}$ by $7^{\circ} \mathrm{C}$ for the three evaporator water temperature sets $(8,15),(10,17)$, and $(12,19)^{\circ} \mathrm{C}$. The performance was studied by the effects of evaporator and condenser inlet water temperatures on the system COP, refrigerant flow, evaporator, and condenser pressures at steady state conditions. The refrigerant flow rate was regulated by the compressor speed and also the EEV opening to maintain the refrigeration effect at constant level. Automatic control maintained the system at constant cooling load by regulating refrigerant flow that depended on the compressor speed. EEV opening regulates refrigerant quality and quantity depending on refrigerant superheat. Figure 5 , demonstrates that increasing $\mathrm{T}_{\mathrm{c}, \mathrm{w}, \mathrm{i}}$ leads to increase refrigerant flow by increasing compressor speed to maintain refrigeration rate at the constant value which is decreased from increasing condenser pressure.

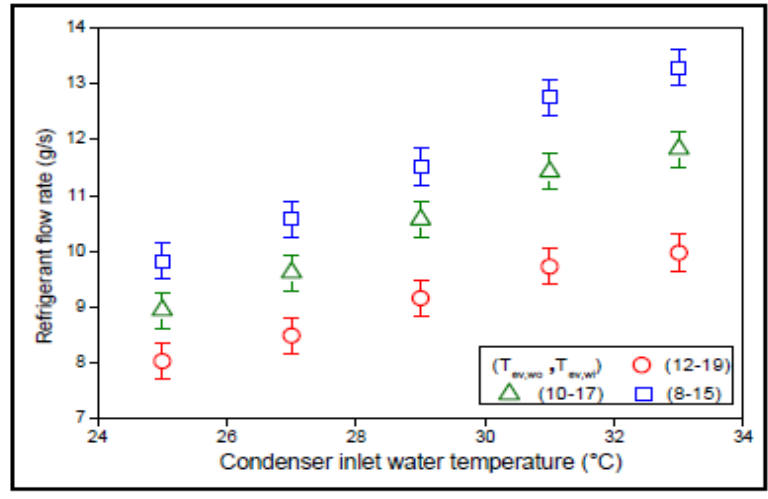

Figure 5: Refrigerant flow rate versus Tc,w,i at the three sets of Te,w,i

The refrigerant mass flow rate rises when the inlet temperature of the evaporator decreases. This increase in the mass flow rate is necessary to keep the cooling capacity constant by compensating the effect of the reduction in the refrigeration effect. The increase in $T_{e, w, i}$ enlarges the vapor density at the compressor suction line, as shown in Figure 6, and enhances the volumetric efficiency, as stated by Eq. (7). Therefore, the controller reduces the compressor speed when $T_{e, w, i}$ becomes high as the refrigeration effect improves which allows the reduction in the refrigerant mass flow rate. The volumetric efficiency is inversely proportional to the compression ratio. At constant condenser pressure, the compression ratio decreases with the increase in the evaporator pressure [16]. 


$$
\begin{gathered}
\dot{m_{r}}=\eta_{v} \times N \times V_{d} \times \rho_{v} \\
\eta_{v}=1-\frac{V_{c}}{V_{d}} \times\left[\left(\frac{P_{c}}{P_{e}}\right)^{C_{v} / C_{p}}-1\right]
\end{gathered}
$$

Where $\left(\dot{m}_{r}\right)$ is the refrigerant flow rate, $(\eta v)$ compressor volumetric efficiency, $(N)$ compressor speed, $\left(V_{c}\right)$ is a clearance volume of the compressor, $\left(V_{d}\right)$ is its displacement volume, and $(\rho v)$ refrigerant vapor density at evaporator outlet [2].

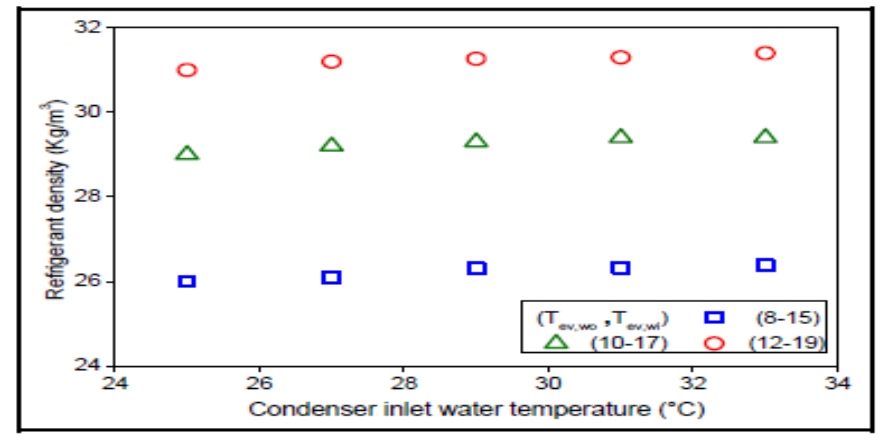

Figure 6: Refrigerant density versus $T_{c, w, i}$ at the three sets of $T_{e, w, i}$

The evaporator pressure $\left(\mathrm{P}_{\mathrm{e}}\right)$ was unaffected by the change in the inlet water temperature of the condenser $\mathrm{T}_{\mathrm{c}, \mathrm{w}, \mathrm{i}}$ as shown in Figure 7.

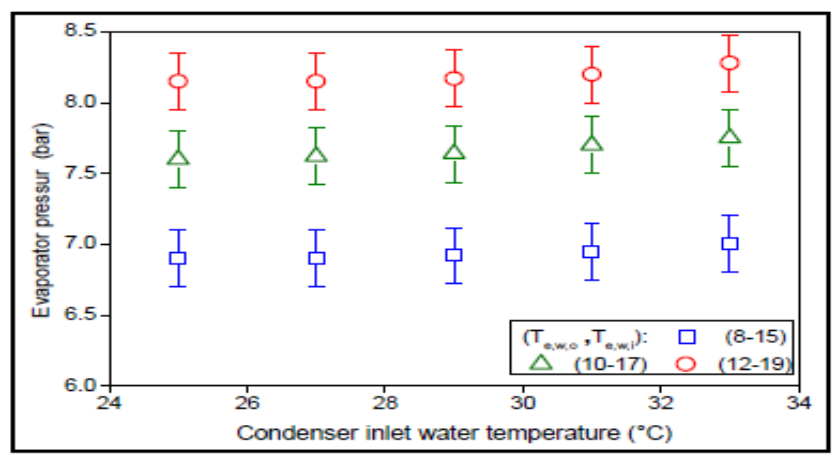

Figure 7: Evaporator pressure versus Tc,w,i at the three sets of Te,w,i

The effect of $T_{e, w, i}$ on the condenser pressure can be slightly seen only at high $T_{c, w, i}$ however, the condenser pressure is a function of the temperature $T_{c, w, i}$ only as shown in Figure 8.

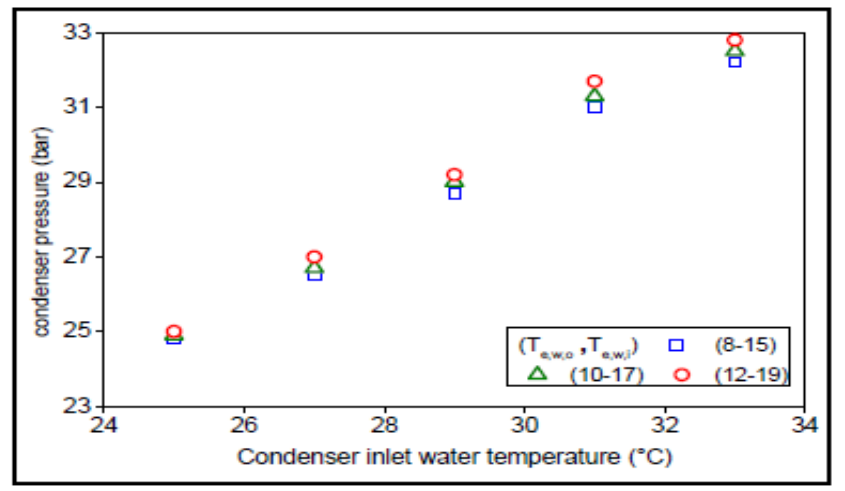

Figure 8: Condenser pressure versus $T_{c, w, i}$ at the three sets of $T_{e, w, i}$ 
The EEV opening was regulated to maintain degree of superheat at $7^{\circ} \mathrm{C}$. The degree of refrigerant superheat depends on the refrigeration effect and refrigerant flow that relate to evaporator pressure and compressor speed respectively. The EEV opening increase when the $T_{c, w, i}$ increases or $T_{e, w, i}$ decrease due to increase compressor speed and to decrease refrigeration effect, as shown in Figure 9.

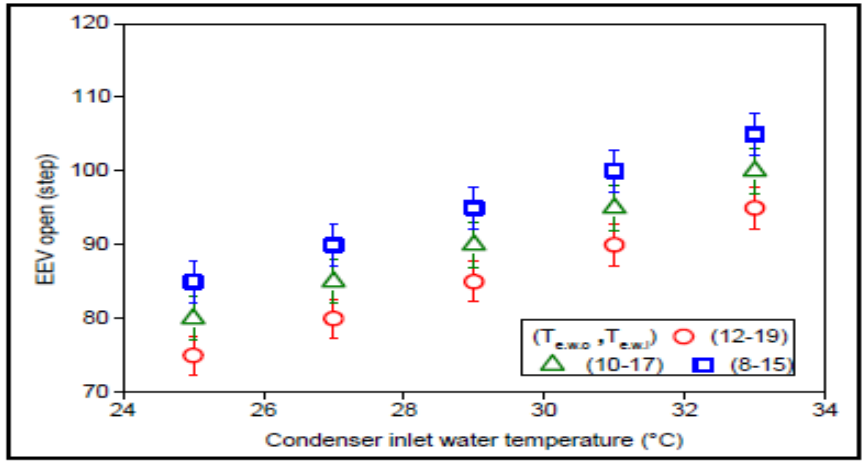

Figure 9: EEV opening versus Tc,w,i at the three sets of Te,w,i

The compressor speed is directly proportioned to $\mathrm{T}_{\mathrm{c}, \mathrm{w}, \mathrm{i}}$ to maintain cooling capacity that decreased with increasing $\mathrm{P}_{c}$ as shown in Figure 10. The increase in the $\mathrm{P}_{\mathrm{e}}$ decreases compressor speed because the refrigerant vapor density becomes higher. Consequently, the refrigerant flow rate is raised.

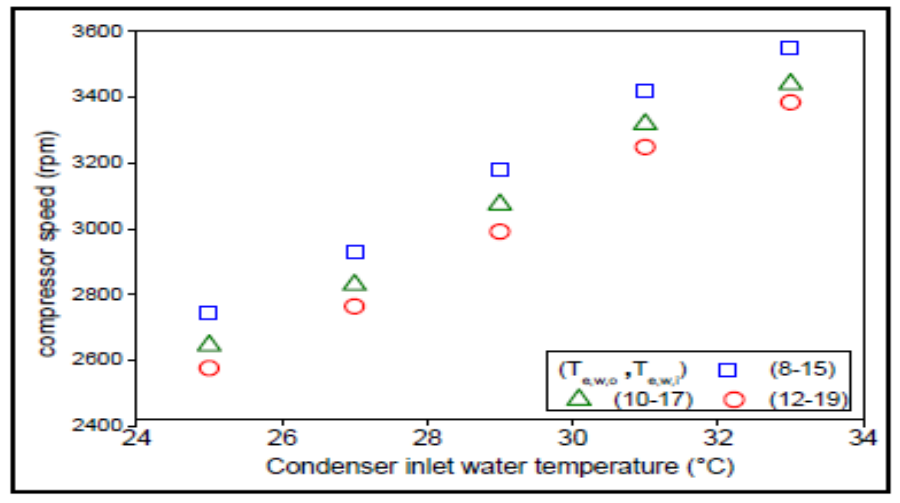

Figure 10: Compressor speed versus Tc,w,i at the three sets of Te,w,i

The increase in the compressor speed and compression ratio raises the power consumption that related to the effects of increasing evaporator and condenser temperatures as shown in Figure 11.

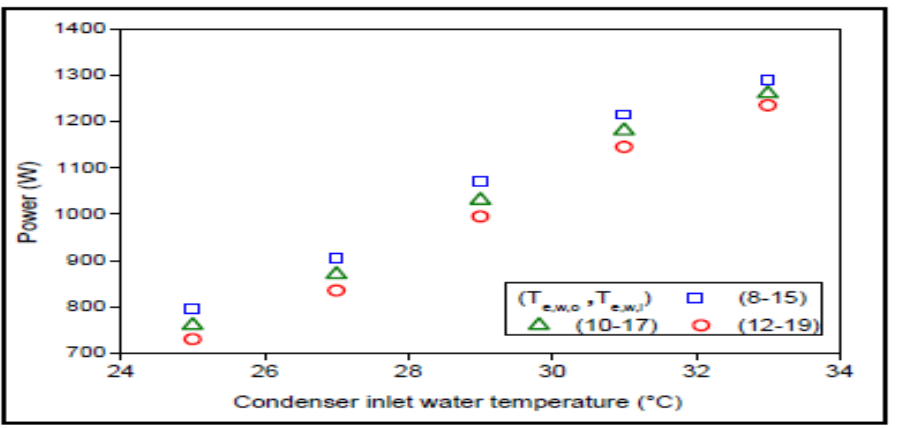

Figure 11: Compressor power versus Tc,w,i at the three sets of Te,w,i

Increasing condenser inlet water temperature increases refrigerant subcooling that was directed proportion to condenser working pressure due to increase condenser heat exchanging efficiency at high temperatures. Also, refrigerant subcooling was directly proportioned with evaporator inlet water temperature because of decreasing refrigerant flow at high evaporation temperatures as shown in Figure 12. 


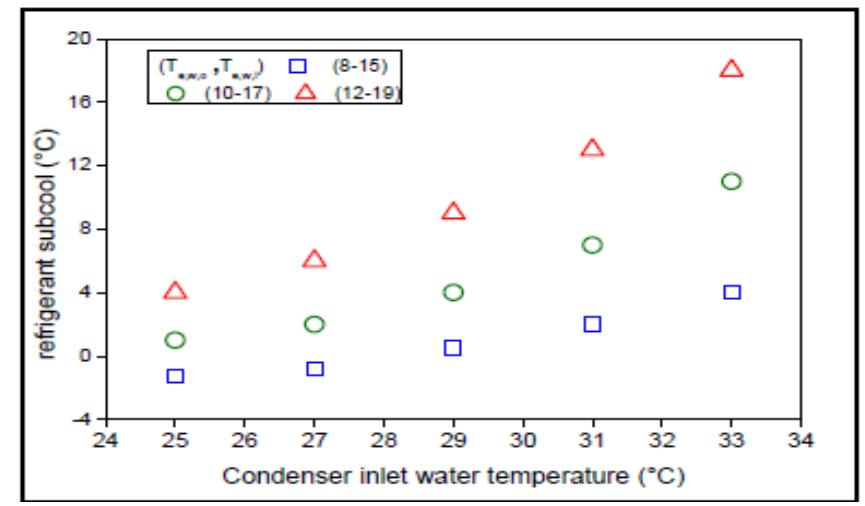

Figure 12: Refrigerant subcooled versus Tc,w,i at the three sets of Te,w,i

Increasing $\mathrm{T}_{\mathrm{c}, \mathrm{w}, \mathrm{i}}$ reflected on increasing pressure ratio and compressor speed to maintain refrigeration effect at constantan level by increasing refrigerant flow which decreases COP value due to increases power required at constant cooling load as shown in Figure 13, and also increasing $T_{e, w, i}$ results in decreasing pressure ratio and compressor speed. The desired indicator here increasing $\mathrm{T}_{\mathrm{e}, \mathrm{w}, \mathrm{i}}$ for $2^{\circ} \mathrm{C}$ results in increasing COP about $3.3 \%$.

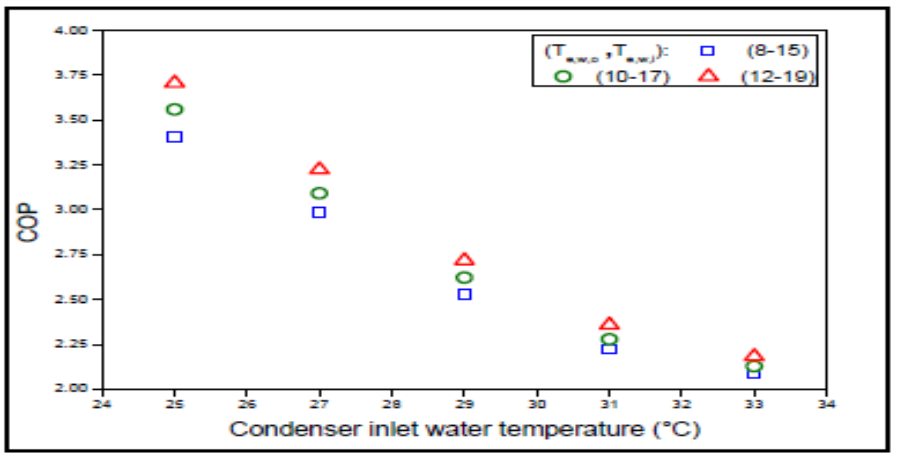

Figure 13: System COP versus $T_{c, w, i}$ at the three sets of $T_{e, w, i}$

\section{Conclusions}

The effect of the evaporator and condenser inlet water temperature of refrigeration chilled water system with a variable speed compressor and EEV was experimentally investigated at constant cooling load. At constant evaporator inlet water temperature, increasing condenser inlet water temperature increases the condenser pressure. This raises the refrigerant flow rate due to high compressor speed. The COP was reduced from $\left(3.7\right.$ at $\left.\mathrm{T}_{\mathrm{c}, \mathrm{w}, \mathrm{i}} 25^{\circ} \mathrm{C}\right)$ to $\left(2.18\right.$ at $\left.\mathrm{T}_{\mathrm{c}, \mathrm{w}, \mathrm{i}} 33^{\circ} \mathrm{C}\right)$ due to high compressor power consumption resulted from the increase in the compression ratio and compressor speed. At constant condenser inlet water temperature, high evaporator inlet water temperature raises the evaporator pressure that reduces the refrigerant flow rate due to the increases in the refrigerant vapor density at the compressor suction line. System COP was enhanced by $3.3 \%$ with increasing $\mathrm{T}_{\mathrm{e}, \mathrm{w}, \mathrm{i}}$ for $2^{\circ} \mathrm{C}$ due to the reduction in the compressor speed and also in the compression ratio. Refrigerant subcooled was dependent on the condenser pressure and refrigerant flow. The refrigerant subcooling is directly proportional to the condenser temperature. Therefore, the increase of evaporator inlet water temperature increases system efficiency in contrast to the increasing of condenser inlet water temperature that reduces efficiency.

\section{Abbreviations:}

A/C: Air condition system.

COP: Coefficient of performance.

$C_{w}$ : Specific heat of water, $\mathrm{kJ} / \mathrm{kg} .{ }^{\circ} \mathrm{C}$.

DS: Degree of refrigerant superheat, ${ }^{\circ} \mathrm{C}$.

DX: direct expansion systems. 
EEV: Electronic expansion valve.

$K_{i}$ : Integral gain of PI-controller.

$K_{p}$ : Proportional gain of PI-controller.

$\dot{m}$ : Mass flow rate, $\mathrm{kg} / \mathrm{s}$.

$N$ : Compressor speed, rpm.

$P$ : Pressure, bar.

PI: Proportional integral controller.

Q: Heat transfer rate, $\mathrm{W}$.

R410a: Refrigerant of 50\% R32 and 50\% R 125 .

$T$ : Temperature, ${ }^{\circ} \mathrm{C}$.

$U$ : Uncertainty.

VSRs: variable speed refrigeration system.

$V_{d}$ : Compressor displacement volume, $\mathrm{m}^{3} / \mathrm{rev}$.

$V_{c}$ : Compressor clearance volume, $\mathrm{m}^{3} / \mathrm{rev}$.

$W$ : Power, W.

\section{Greek symbols:}

$\eta_{v}$ : Volumetric Efficiency.

$\rho$ : Density, $\mathrm{kg} / \mathrm{m}^{3}$.

$\sigma$ : Standard deviation.

\section{Subscripts:}
$c$ : Condenser.
$e$ : Evaporator.
$i$ : Inlet.
$o$ : Outlet.
$r$ : Refrigerant.
$s$ : Saturation.
$w$ : Water.

\section{References}

[1] J. Lim, M. S. Yoon, T. Al-Qahtani, Y. Nam, Feasibility study on variable-speed air conditioner under hot climate based on real-scale experiment and energy simulation, Energies , 12 (2019) 1489. https://doi.org/10.3390/en12081489

[2] R. N. N. Koury, L. Machado, K. A. R. Ismail, Numerical simulation of a variable speed refrigeration system, Int. J. Refrig., 24 (2001) 192-200. https://doi.org/10.1016/S0140-7007(00)00014-1

[3] C. Aprea, R. Mastrullo, C. Renno, Experimental analysis of the scroll compressor performances varying its speed, Appl. Therm. Eng., 26 (2006). 983-992. https://doi.org/10.1016/j.applthermaleng.2005.10.023

[4] T. Qiu, Z. Lina, C. Wei, G. Xiujuan, Y. Xiaojun, D. Chenmian, Control strategy of compressor and subcooler in variable refrigerant flow air conditioning system for high EER and comfortable indoor environment, Appl. Therm. Eng., 141 (2018) 215-225. https://doi.org/10.1016/j.applthermaleng.2018.05.118

[5] Y. Xia, J. Du, S. Deng, Effects of superheat nonlinearity on the operational stability of a direct expansion (DX) air conditioning (A/C) system, Energy Procedia, 142 (2017) 1854-1859. https://doi.org/10.1016/j.egypro.2017.12.575

[6] X. Yudong, D. Qiang, J. Zhoushu, D. Shiming, S.Mengjie, Development of a superheat controller for mitigating hunting in a direct expansion air conditioning system, Energy Procedia, 158 (2019) 2085-2091. https://doi.org/10.1016/j.egypro.2019.01.481

[7] A. Varchmin, M. Gräber, W. Tegethoff, J. Köhler, Superheat control with a dynamic inverse model, in Proceedings of the 10 th International Modelica Conference, Lund, Sweden, Linköping University Electronic Press, 2014, 867-873. https://doi.org/10.3384/ECP14096867 
[8] H. Yan, Y. Xia, S. Deng, Adaptive control for degree of refrigerant superheat in a direct expansion air conditioning system under variable speed operation, Energy Procedia, 158 (2019) 2182-2187. https://doi.org/10.1016/j.egypro.2019.01.618

[9] Y. Guo, G. Li, H. Chen, Y. Hu, L. Shen, H. Li, M. Hu, J. Li, Development of a virtual variable-speed compressor power sensor for variable refrigerant flow air conditioning system,Développement d'un capteur de puissance de compresseur virtuel à vitesse variable pour un système de conditionnement d'air à débit de frigorigène variable, Int. J. Refrig., 74 (2017) 73-85. https://doi.org/10.1016/j.ijrefrig.2016.09.025

[10] D. Praic, A. Vicovac, V. Stojanovic, The static characteristic of the evaporator superheat control loop, Presented at the XIII International SAUM Conference on Systems, Automatic Control and Measurements November 09th-11th, Niš, Serbia, 2016.

[11] H. Nasution, A. A. Aziz, Z. A. Latiff, PI control Application for building Air Conditioning System, J. Teknol., 75 (2015) 61-69.

[12] Y. Xie, X. Tang, B. Song, X. Zhou, Y. Guo, Model-free tuning strategy of fractional-order PI controller for speed regulation of permanent magnet synchronous motor, 23-35. https://doi.org/10.1177/0142331217751040

[13] Z. Gao, Scaling and bandwidth-parameterization based controller tuning, Proceedings of the 2003 American Control Conference, 2003., Denver, CO, USA, 2003,4989-4996. https://doi.org/10.1109/ACC.2003.1242516

[14] R. J. Moffat, Contributions to the theory of single-sample uncertainty analysis, J. Fluids Eng., 104 (1982) 250-258. https://doi.org/10.1115/1.3241818

[15] R. J. Moffat, Describing the uncertainties in experimental results, Exp. Therm. Fluid Sci., 1 (1988) 3-17. https://doi.org/10.1016/0894-1777(88)90043-X

[16] L. Zhao, M. Zaheeruddin, Dynamic simulation and analysis of a water chiller refrigeration system, Appl. Therm. Eng., 25 (2005) 2258-2271. https://doi.org/10.1016/j.applthermaleng.2005.01.002 